\title{
Unambiguous NMR Structural Determination of (+)-Catechin-Laccase Dimeric Reaction Products as Potential Markers of Grape and Wine Oxidation
}

\author{
Stacy Deshaies, Christine le Guernevé, Lucas Suc, Laetitia Mouls, François Garcia and Cédric Saucier *(D)
}

check for updates

Citation: Deshaies, S.; le Guernevé,

C.; Suc, L.; Mouls, L.; Garcia, F.;

Saucier, C. Unambiguous NMR Structural Determination of

(+)-Catechin-Laccase Dimeric Reaction Products as Potential

Markers of Grape and Wine

Oxidation. Molecules 2021, 26, 6165.

https: / / doi.org/10.3390/

molecules 26206165

Academic Editors: Dalene De Beer,

Lizette Joubert, Elisabetta Damiani and Tiziana Bacchetti

Received: 15 September 2021

Accepted: 7 October 2021

Published: 13 October 2021

Publisher's Note: MDPI stays neutral with regard to jurisdictional claims in published maps and institutional affiliations.

Copyright: (C) 2021 by the authors. Licensee MDPI, Basel, Switzerland. This article is an open access article distributed under the terms and conditions of the Creative Commons Attribution (CC BY) license (https:/ / creativecommons.org/licenses/by/ $4.0 /)$.
SPO, Université de Montpellier, INRAE, Institut Agro, 34000 Montpellier, France; stacy.deshaies@umontpellier.fr (S.D.); christine.le-guerneve@inrae.fr (C.1.G.); lucas.suc@inrae.fr (L.S.); laetitia.mouls@supagro.fr (L.M.); francois.garcia@umontpellier.fr (F.G.)

* Correspondence: cedric.saucier@umontpellier.fr

Abstract: (+)-Catechin-laccase oxidation dimeric standards were hemi-synthesized using laccase from Trametes versicolor in a water-ethanol solution at $\mathrm{pH}$ 3.6. Eight fractions corresponding to eight potential oxidation dimeric products were detected. The fractions profiles were compared with profiles obtained with two other oxidoreductases: polyphenoloxidase extracted from grapes and laccase from Botrytis cinerea. The profiles were very similar, although some minor differences suggested possible dissimilarities in the reactivity of these enzymes. Five fractions were then isolated and analyzed by 1D and 2D NMR spectroscopy. The addition of traces of cadmium nitrate in the samples solubilized in acetone- $d_{6}$ led to fully resolved NMR signals of phenolic protons, allowing the unambiguous structural determination of six reaction products, one of the fractions containing two enantiomers. These products can further be used as oxidation markers to investigate their presence and evolution in wine during winemaking and wine ageing.

Keywords: oxidation marker; (+)-catechin; phenolic NMR signals; laccase; cadmium nitrate; polyphenol oxidase

\section{Introduction}

Polyphenols are a family of chemical compounds widely present in nature. They are found in significant amount in tea [1], cacao [2,3], blueberries [4], grapes [5], and fermented products like wine [6]. Being primary oxidation targets [7,8], polyphenols chemical structures continually evolve. These changes impact the organoleptic properties of many types of food; they are responsible for phenomena such as food browning [9] and modifications of wine's sensory characteristics [10,11]. In enology, this oxidation phenomenon takes place in grapes or wines. Concerning enzymatic oxidation, the main enzymes responsible for browning are oxidoreductases, more precisely, polyphenol oxidase present in grapes and laccase produced by Botrytis cinerea [12].

Enzymatic oxidation mainly occurs in grape must, but further wine browning may be due to chemical oxidation reactions $[7,13]$ or to Botrytis cinerea laccase that can be very stable during wine ageing [14]. Two oxidation enzymatic activities may occur on phenolic substrates: monophenol oxidase activity characterized by the hydroxylation of an existing hydroxyl group adjacent position and diphenol oxidase activity corresponding to the oxidation of ortho-dihydroxybenzenes to ortho-benzoquinones.

According to the Nomenclature Committee of the International Union of Biochemistry and Molecular Biology (NC-IUBMB), these enzymatic activities are catalyzed by E.C.1-class enzymes corresponding to oxidoreductases. Among them, the three main classes of oxidoreductases catalyzing polyphenol oxidation are E.C.1.14.18.1 (monophenol monooxygenase), E.C.1.11.1 (peroxidase/POD), and E.C.1.10.3 (oxidoreductases acting on diphenols). 
This last class is divided in different subclasses, and two of them appeared particularly interesting for this study: E.C.1.10.3.1 (polyphenol oxidase/PPO) and E.C.1.10.3.2 (laccase) (See Supplementary Materials Figure S1).

PPO, laccase, and peroxidase are the oxidoreductases mainly responsible for browning during grape processing [13]. Browning caused by POD is negligible in fruits but can increase phenols degradation when combined with PPO [15]. PPO are naturally present in grapes and are able to catalyze the oxidation of monophenols to catechols and of catechols to brown pigments $[8,13,16]$. Laccases, occurring in Botrytis-infected grapes, have a wider action spectrum [17] as they can catalyze the oxidation of many different substrates. The main laccases' oxidation targets remain 1-2 and 1-4 dihydroxybenzene.

In wine, benzoquinone produced by oxidation (PPO or laccases) can easily undergo further reactions depending on their redox properties and electronic affinities [15]. They can either act as electrophiles and react with amino derivatives [18] or act as oxidants and react, among others, with phenolic substrates. Depending on their chemical conformation (quinone or semi-quinone), benzoquinone can lead to different oxidation reaction products. At a neutral $\mathrm{pH},(+)$-catechin will be oxidized to quinone on the A-ring position $\mathrm{C} 5$ or $\mathrm{C7}$ and lead to the formation of six possible dimeric isomers implying a linkage between the B-ring position $\mathrm{C}^{\prime}{ }^{\prime}, \mathrm{C}^{\prime}$, or $\mathrm{C}^{\prime}$ of the upper catechin unit and the A-ring position $\mathrm{C} 6$ or $\mathrm{C} 8$ of the lower unit $[19,20]$. Dehydrodicatechin is a well-known product of this coupling [21]. The labeling positions of the structures are displayed in Figure 1. Under acidic conditions, semi-quinone forms can also be present on the B-ring (position $\mathrm{OH}^{\prime}$ or $\mathrm{OH}^{\prime}$ ) and lead to four possible dimeric isomers [20,22] with the upper catechin unit and the A-ring of the lower unit (position C6 or C8). Catechin enzymatic oxidation was investigated in previous studies [22,23], and the associated oxidation products were characterized by HPLC [24], though more rarely isolated and never completely characterized by NMR.

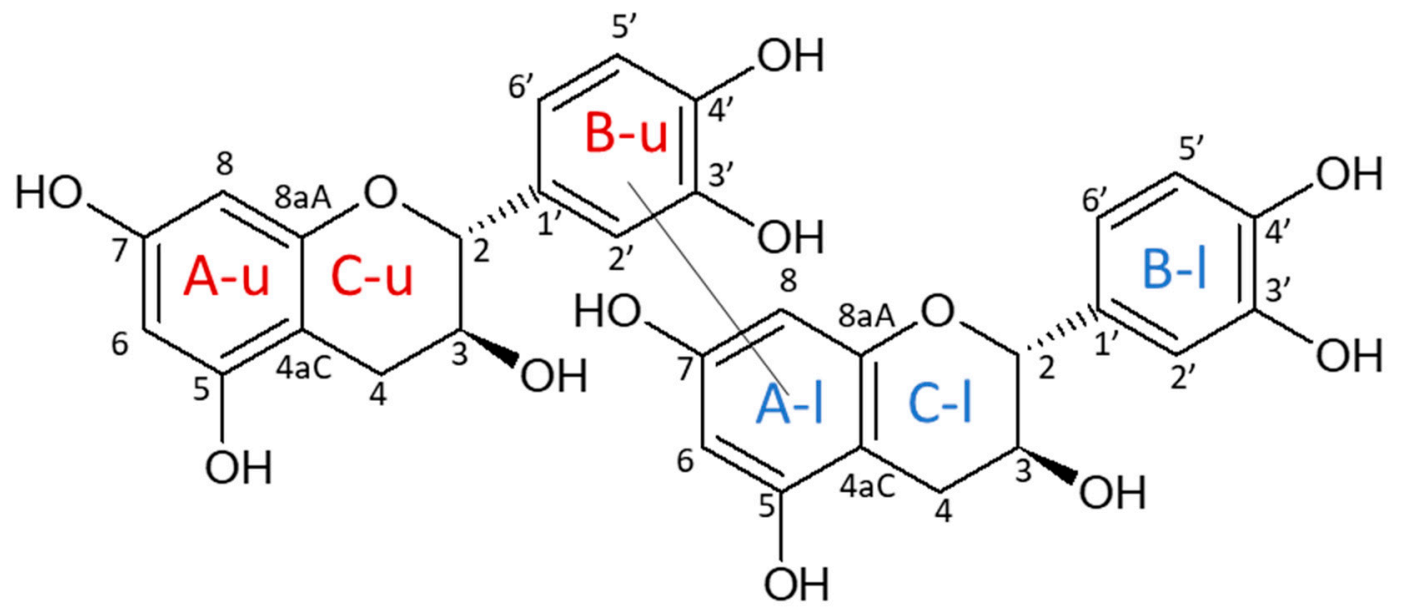

Figure 1. Example of a dimeric oxidation product. A, B, C rings are labelled with $\mathrm{u}$ for upper units and with 1 for lower units.

The aim of this work was first to compare by UHPLC-MS the dimeric (+)-catechin oxidation products profiles in the presence of three oxidoreductase extracts, i.e., PPO extracted from grapes, laccase from the fungus Botrytis cinerea present in botrytized sweet wines [14], and laccase from Trametes versicolor.

The second objective was to hemisynthesize and characterize the structures of some dimeric oxidation products by NMR spectroscopy obtained with laccase from Trametes versicolor. 


\section{Results and Discussion}

2.1. Comparison of Dimeric Reaction Products Profiles with Three Different Oxydoreductases and (+)-Catechin

$(+)$-Catechin was first oxidized in the presence of laccase from Trametes versicolor at $\mathrm{pH} 3.6$ in the model wine solution. After separation of the dimeric fraction from residual (+)catechin and other polymeric fractions, eight major fractions were collected and analyzed by UHPLC-UV-MS, noted from N1 to N8 in increasing retention time order (Table 1). The electrospray mass spectra in positive mode showed the ion peaks $[\mathrm{M}+\mathrm{H}]^{+}$at $m / z 579$ for N1 to N6, hypothetically corresponding to a dimer formed by a single bond between two catechin units, and $[\mathrm{M}+\mathrm{H}]^{+}$at $m / z 577$ for N7 and N8, hypothetically suggesting the formation of an additional linkage.

Table 1. Analytical reversed-phase UHPLC retention times, absorbance maxima, corresponding $\mathrm{m} / \mathrm{z}$ (Th), and yields (\%) for the eight major oxidation products collected.

\begin{tabular}{ccccc}
\hline Compound & $\mathbf{R}_{\mathbf{t}}(\mathbf{m i n})$ & $\boldsymbol{\lambda}_{\max }(\mathbf{n m})$ & $m / z(\mathbf{T h})$ & Molar Yield $(\%)$ \\
\hline N1 & $6.14 \pm 0.02$ & 280 & 579 & 0.4 \\
N2 & $6.91 \pm 0.02$ & 280 & 579 & 0.1 \\
N3 & $10.34 \pm 0.03$ & 280 & 579 & 0.7 \\
N4 & $14.11 \pm 0.07$ & 280 & 579 & 0.3 \\
N5 & $17.13 \pm 0.02$ & 280 & 579 & 0.2 \\
N6 & $19.03 \pm 0.01$ & 280 & 579 & 0.7 \\
N7 & $20.63 \pm 0.03$ & 263,318 & 577 & 0.1 \\
N8 & $25.23 \pm 0.01$ & $256,280,286$ & 577 & 0.2 \\
\hline
\end{tabular}

These eight oxidation fractions were potentially observed after the chemical depolymerization of a tannin fraction in previous works $[25,26]$ and could possibly be the same as those already described by Guyot et al. [20], even if the experimental conditions were slightly different. Indeed, in this previous study, a crude PPO extract was used at $\mathrm{pH} 3$ and 6 to obtain eight fractions. In the present study, three different enzymes were compared at $\mathrm{pH} 3.6$ in the model wine solution. The LC-MS comparative analysis of the major oxidation fractions obtained with the three different enzymes (laccase from Trametes versicolor, laccase from Botrytis cinerea, and polyphenoloxidase extracted from grapes) are presented in Table 2. For each of the eight fractions, the retention times were almost identical with the different enzymes, and similar $m / z$ were determined with the MS analysis. These results support the hypothesis that the same fractions were obtained for each enzyme, containing products with structures similar to those hypothesized by Guyot et al. [20]. López-Serrano and Ros Barceló [27] also performed a comparative study of the (+)-catechin oxidation products with two different enzymes: peroxidase and polyphenoloxidase, both extracted from strawberries. They concluded that the products obtained with the two enzymes were qualitatively the same. An additional compound named $N 4^{\prime}$ with $m / z=578$ Th and $\mathrm{R}_{\mathrm{t}}=15.66 \mathrm{~min}$ was observed in experiments with laccase from Botrytis cinerea and extracted PPO but not with laccase from Trametes versicolor, which suggests possible differences in reactivity for these enzymes.

\subsection{Study and Optimization of Physicochemical Parameters on ${ }^{1} H-N M R$ Phenolic and Aliphatic OH Signals}

The structural characterization of procyanidins dimers can be obtained by NMR analysis. In particular, the precise linkage position between units may be determined using HMBC and/or ROESY correlation spectra [28,29] (Figures S2 and S3). In the case of an ether-type $(\mathrm{C}-\mathrm{O}-\mathrm{C})$ bond, the attribution of the hydroxyl signal protons is necessary. It may also be crucial in the case of $\mathrm{C}-\mathrm{C}$ linkages if some aliphatic or aromatic protons overlap or if some key correlations are missing. However, even in an aprotic solvent, the hydroxyl protons of polyphenols often appear as broad signals from which no structural information can be obtained [30]. This issue was tentatively addressed by the addition of traces of 
$\mathrm{Cd}\left(\mathrm{NO}_{3}\right)_{2}$ in the sample solutions. Indeed, ${ }^{1} \mathrm{H}$ broad signals of $\mathrm{OH}$ groups are due to the intermolecular exchange between these $\mathrm{OH}$ protons and other protons in the solvent or solute. By reducing intermolecular bonds, the presence of cadmium nitrate in the samples may decrease these exchanges, thus improving the sharpness of $\mathrm{OH}$ proton signals.

\subsubsection{Effect of Cadmium Addition}

After freeze-drying, the five fractions N2, N3, N4, N6, and N8 were solubilized in acetone- $d_{6}$. Then, $1 \mathrm{D}$ proton NMR spectra were acquired at $25^{\circ} \mathrm{C}$ before (Figure $2 \mathrm{~A}$ ) and after addition of small amounts of cadmium (Figure 2B). In pure acetone- $d_{6}$, the phenolic $\mathrm{OH}$ protons of all fractions appeared as broad peaks. After the addition of cadmium, these protons showed highly resolved signals in the case of fractions N6 and N8, whereas for fractions N2, N3, and N4 the signals were only a little sharper. It should also be mentioned that increasing the $\mathrm{Cd}$ content had no effect upon $\mathrm{OH}$ signal resolution, as no sharpness or broadness of peak linewidth was observed when successive small amounts of $\mathrm{Cd}$ were added to the samples (data not shown).

Table 2. Qualitative comparison of analytical reversed-phase UHPLC retention times for the eight major oxidation products with the three different oxidative enzymes: laccase from Trametes versicolor, laccase from Botrytis cinerea, and polyphenoloxidase extracted from grapes. The results are expressed as mean values $(n=3)$ with standard deviation.

\begin{tabular}{cccc}
\hline Compound & $\begin{array}{c}\text { Laccase from } \\
\text { Trametes versicolor }\end{array}$ & $\begin{array}{c}\text { Laccase from } \\
\text { Botrytis cinerea }\end{array}$ & $\begin{array}{c}\text { Polyphenoloxidase } \\
\text { Extracted from } \\
\text { Grapes }\end{array}$ \\
\hline N1 & $6.14 \pm 0.02$ & $6.14 \pm 0.02$ & $6.12 \pm 0.01$ \\
N2 & $6.91 \pm 0.02$ & $6.86 \pm 0.01$ & $6.80 \pm 0.01$ \\
N3 & $10.34 \pm 0.03$ & $10.29 \pm 0.02$ & $10.29 \pm 0.01$ \\
N4 & $14.11 \pm 0.07$ & $14.10 \pm 0.01$ & $14.04 \pm 0.05$ \\
N4 & $17.13 \pm 0.02$ & $15.67 \pm 0.01$ & $15.66 \pm 0.05$ \\
N5 & $19.03 \pm 0.01$ & $17.12 \pm 0.04$ & $17.11 \pm 0.06$ \\
N6 & $20.63 \pm 0.03$ & $19.00 \pm 0.003$ & $19.00 \pm 0.03$ \\
N7 & $25.23 \pm 0.01$ & $20.59 \pm 0.01$ & $20.60 \pm 0.03$ \\
N8 & & $25.21 \pm 0.02$ & $25.22 \pm 0.03$ \\
\hline
\end{tabular}

Highly resolved phenolic $\mathrm{OH}$ signals from products N2, N3, and N4 were achieved thanks to additional drying and resolubilization (Figure 2C,D).

The difference of behavior upon $\mathrm{Cd}$ addition between the fractions may be explained by the strength of molecular interactions: stronger in the case of N2, N3, and N4 compared to N6 and N8, a further step being necessary to break these bonds.

This additional step may be the key step when using $\mathrm{Cd}$ to obtain highly resolved phenolic $\mathrm{OH}$ signals in any situation, whatever the origin of the samples, the synthesis reaction, or the natural polyphenolic products.

A previous work dealing with the unambiguous structural characterization of polyphenol dimers using highly resolved $\mathrm{OH}$ phenolic NMR signals thanks to cadmium nitrate addition was published in 1996 [30]. To our knowledge, no other research paper using this methodology has been published since then. Other investigations were subsequently undertaken to reach this goal, either by picric acid dosed additions [31] or by using a low acquisition temperature [32]. This may be explained by the further step necessary to get a decisive effect upon $\mathrm{OH}$ peak sharpness with $\mathrm{Cd}$ addition, as described above. However, cadmium seems to be of great value, since highly resolved signals can be obtained without the need to add precise amounts, in contrast with picric acid or NMR spectra acquisition at low temperatures. 

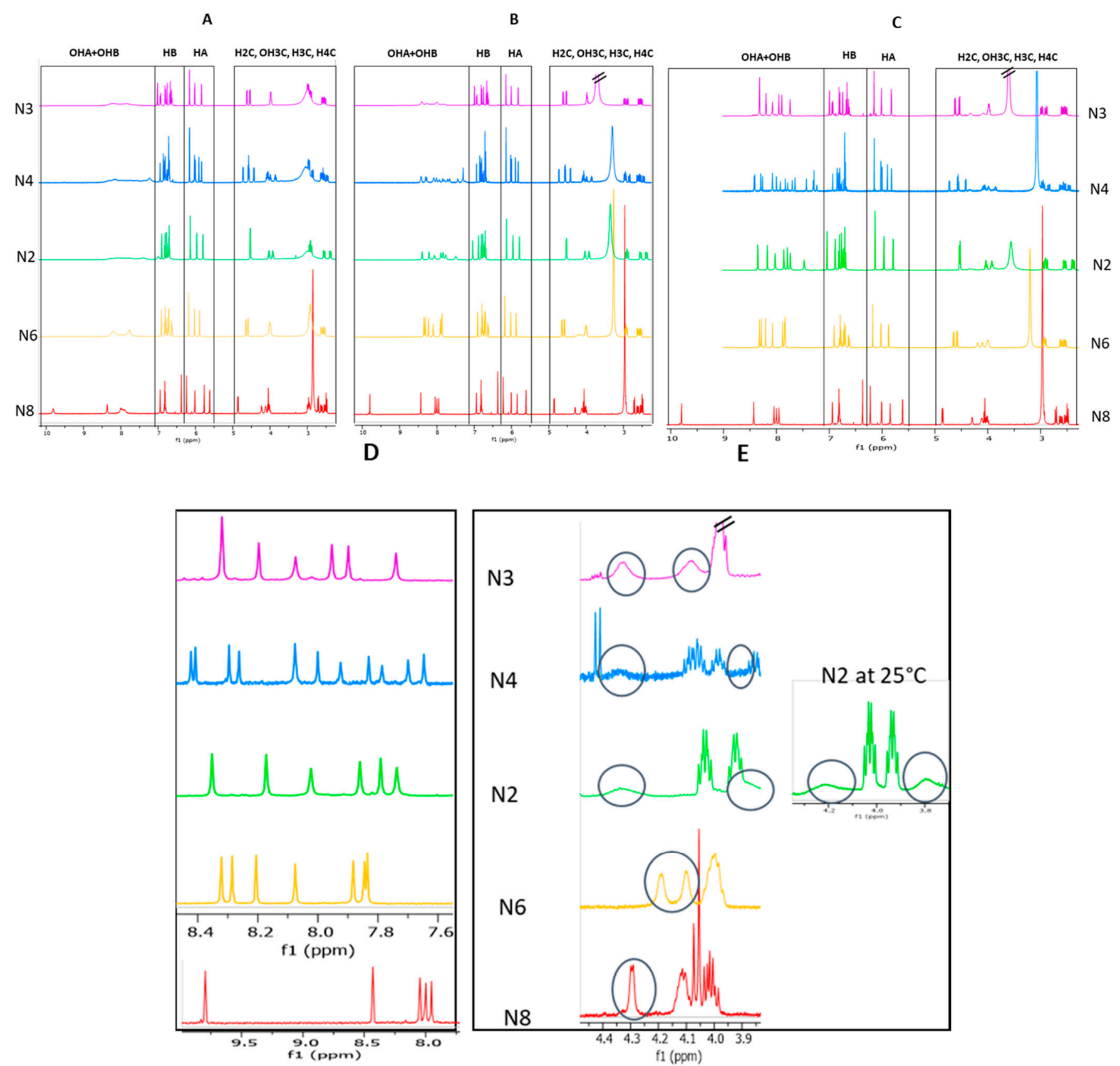

Figure 2. Image of $1 \mathrm{D}^{1} \mathrm{H}$ spectra of the fractions $\mathrm{N} 2, \mathrm{~N} 3, \mathrm{~N} 4, \mathrm{~N} 6$, and $\mathrm{N} 8$ at $25^{\circ} \mathrm{C}$, solubilized in acetone- $d_{6}(\mathbf{A})$, at $25^{\circ} \mathrm{C}$ in acetone- $d_{6}$ in the presence of cadmium (B), at $15{ }^{\circ} \mathrm{C}$ in acetone- $d_{6}$ in the presence of $\mathrm{Cd}$ (with an additional step consisting in dryness evaporation of the fractions $\mathrm{N} 2, \mathrm{~N} 3$, and N4) (C), expansion of the phenolic (D) and the aliphatic (E) $\mathrm{OH}$ regions in the same physicochemical conditions as in (C).

\subsubsection{Effect of the Temperature}

A decrease of the temperature from $25^{\circ} \mathrm{C}$ to $15^{\circ} \mathrm{C}$ had no impact on the sharpness of phenolic $\mathrm{OH}$ or aliphatic $\mathrm{OH}$ signals. Nevertheless, downfield shifts of exchangeable proton peaks allowed us to separate some overlapping phenolic and aliphatic $\mathrm{OH}$ signals, making their identification more obvious (Figure 3). By decreasing the temperature, the proton exchange rate was reduced, and one might expect sharper aliphatic $\mathrm{OH}$ peaks [31]. The temperature of $15^{\circ} \mathrm{C}$ is obviously not low enough to obtain well-resolved aliphatic $\mathrm{OH}$ signals. However, it allowed us to clearly identify the resonance of two aliphatic $\mathrm{OH}$ protons in samples N3 and N6 and of one in sample N8. The spectrum of sample N2 also 
exhibited two $\mathrm{OH}$ aliphatic protons signals, which were more distinguishable at $25^{\circ} \mathrm{C}$ than at $15^{\circ} \mathrm{C}$ (Figure 2E). In the case of the sample N4, the signals arising from aliphatic $\mathrm{OH}$ were only partly visible in the spectra, whether the temperature was set at $25^{\circ} \mathrm{C}$ or to $15^{\circ} \mathrm{C}$, due to persistent overlapping (Figure 2E).

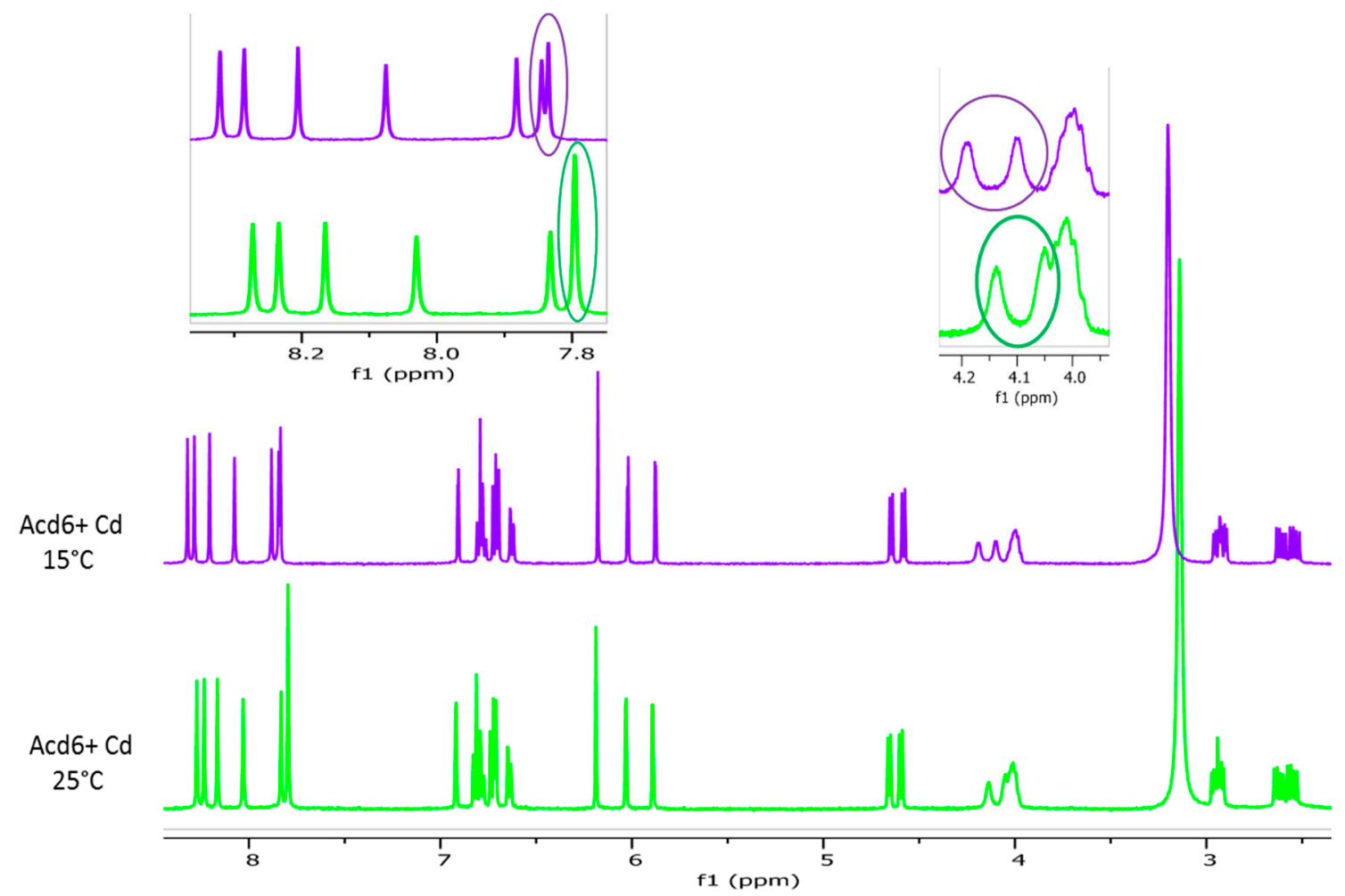

Figure 3. Image of $1 \mathrm{D}^{1} \mathrm{H}$ spectra of fraction N6 in acetone- $d_{6}$ in the presence of $\mathrm{Cd}$ at $25^{\circ} \mathrm{C}$ and $15{ }^{\circ} \mathrm{C}$. The expansions show the effect of temperature upon the aromatic and aliphatic $\mathrm{OH}$ signal chemical shifts.

\subsection{Structural Characterization of the Dimeric Standards-NMR Spectrum Analysis}

The NMR spectra of fractions N2, N3, N4, N6, and N8 showed that the oxidation products were of high purity, since the signal intensities of other detected compounds were less than $10 \%$ compared to those of these products.

In all spectra, four ${ }^{1} \mathrm{H}$ chemical shift regions typical of catechin units may be distinguish (Figure 2C): signals of the aliphatic protons of pyran rings (C rings) are found in the region from 2.3 to $5.0 \mathrm{ppm}$, and those of the aromatic signal protons of resorcinol rings (A rings) and of catechol rings (B rings) from 5.5 to $6.3 \mathrm{ppm}$ and 6.3 to $7.1 \mathrm{ppm}$, respectively. The $\mathrm{OH}$ phenol signals of both $\mathrm{A}$ and $\mathrm{B}$ rings appeared from 7.1 to $10 \mathrm{ppm}$. The NMR spectra of both fractions showed the presence of distinct signal sets of catechin units in a constant intensity ratio: two sets of signals were observed in the spectra of fractions N2, $\mathrm{N} 3, \mathrm{~N} 6$, and $\mathrm{N} 8$ in accordance with the presence of dimers, and four sets in the N4 spectra, which can correspond to one tetramer, two dimers, or a mixture of different oligomers, that is, one trimer plus one monomer. In order to determine the degree of oligomerization of the products present in fraction $\mathrm{N} 4$, an ${ }^{1} \mathrm{H}$ DOSY experiment was performed using a mixture containing aliquots of both fractions N4 and N2. The diffusion coefficients of all signals displayed similar values (Figure 4), indicating the presence of two dimers of catechin in fraction N4. 


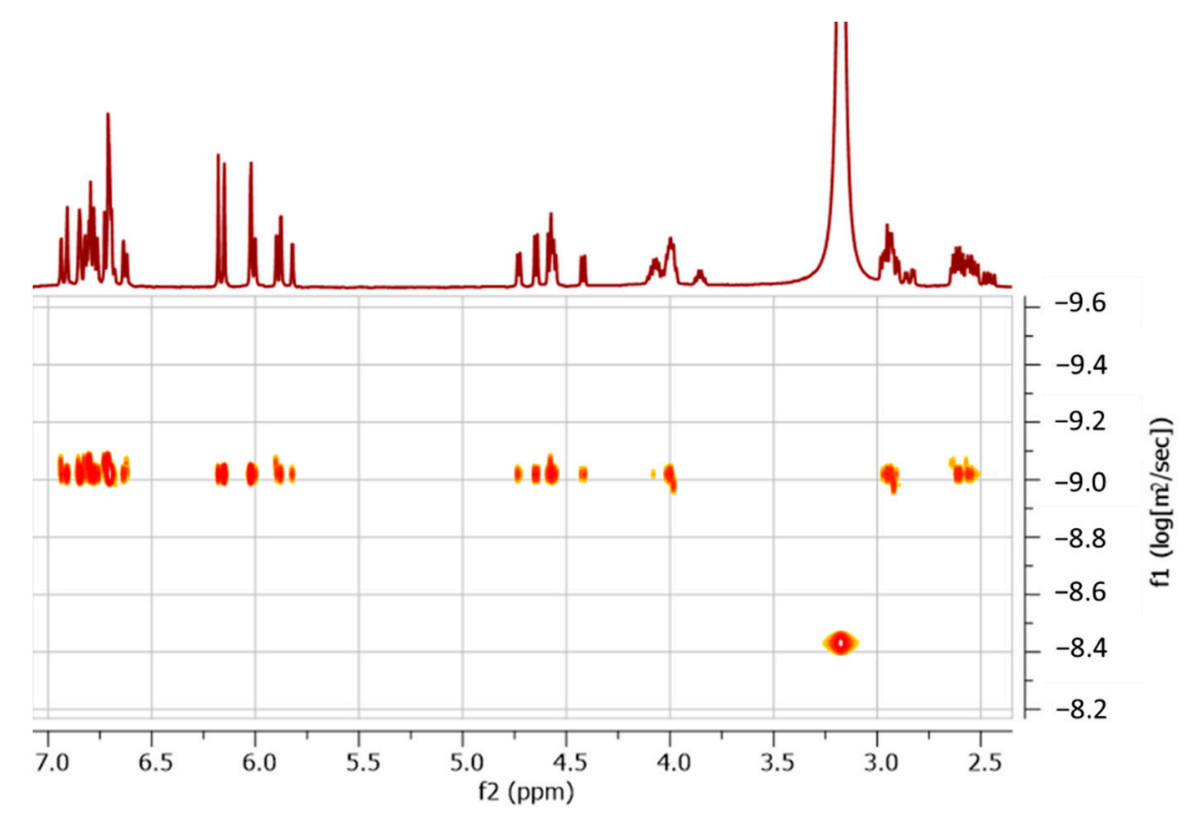

Figure 4. Image of $2 \mathrm{D}^{1} \mathrm{H}$ DOSY spectra of a sample containing both fractions N4 and N2.

Thanks to the fully resolved $\mathrm{OH}$ phenol signals which provide reliable quantitative results, the type of linkage between the catechin units may be directly deduced from peak surface area integration. Thus, for both fractions N3 and N6, the lack of one OH phenol (belonging either to a resorcinol or to a catechol ring) and the lack of one resorcinol aromatic proton indicated an interflavanic linkage (IFL) of ether type implying an O position in an $\mathrm{A}$ or $\mathrm{B}$ ring and a $\mathrm{C} 6$ or $\mathrm{C} 8$ position in an $\mathrm{A}$ ring. In the case of sample N2, two aromatic protons were lacking, one of a $B$ ring and one of an A ring, implying a CA-CB IFL. The 1D ${ }^{1} \mathrm{H}$ spectrum of fraction $\mathrm{N} 4$ showed that two protons of the $\mathrm{B}$ ring were lacking, as well as two protons of the A ring. The bonds between the dimer units of fraction N4 are thus both of the $\mathrm{C}-\mathrm{C}$ type. The spectra of fraction $\mathrm{N} 8$ were quite different from the four others. Some signals were typical of catechin units, in which three $\mathrm{OH}$ phenols, one aromatic $\mathrm{A}$ ring, and one $\mathrm{B}$ ring protons were lacking, as well as one aliphatic $\mathrm{OH}$. On the other hand, some other NMR signals are atypical of a catechin unit: a methylene with deblinded ${ }^{13} \mathrm{C}$ chemical shifts ( 40 ppm) and a ketone group ( 192 ppm).

The proton spin systems of $\mathrm{C}, \mathrm{A}$, and $\mathrm{B}$ rings were determined using both ${ }^{1} \mathrm{H} 1 \mathrm{D}$ and ${ }^{1} \mathrm{H}$ 2D TOCSY spectra (not shown). Two ABMX C-ring spin systems (typical of catechin) were observed in the spectra of fractions N2, N3, N6, and N8, and four for fraction N4. In the spectra of fractions N2, N3, N6, and N8, two meta-coupled doublets $(\mathrm{J} 2 \mathrm{~Hz})$ and a singlet in the aromatic A ring region were assigned, respectively, to the A ring protons of the non-linked catechin unit and to the A ring residual proton of the of C6- or C8-linked catechin unit. In the spectra of N4, due to the presence of two dimers, four meta-coupled doublets and two singlets were detected and assigned as described above. The B ring proton systems were also easily determined from these spectra and allowed us to identify two ABM proton spin systems for the dimers of fractions N3 and N6, whereas one ABM and one $A B$ proton spin systems were detected for dimer $N 2$, and one $A B M$ and one $A M$ proton spin systems for dimer N4. The dimer N8 exhibited only one ABM B-ring spin system typical of a catechin monomer.

2.3.1. Determination of the A Ring Position of the IFL of the Dimers of Fractions N2, N3, $\mathrm{N} 4$, and N6

The establishment of the bridge location on the A ring of dimers (i.e., C6A- or C8Aposition) requires the attribution of the residual HA proton of the CA-linked catechin unit. Thanks to the highly resolved phenolic $\mathrm{OH}$ signals, an easy starting point was the identification of the two $\mathrm{OH}$ phenol protons of the $\mathrm{A}$ ring-linked units, i.e., the A ring that 
had one isolated ${ }^{1} \mathrm{H}$ spin. This may be achieved using ${ }^{1} \mathrm{H}_{-}{ }^{13} \mathrm{C}$ long-range correlations, as illustrated in Figure 5. The OH5A was readily identified thanks to a correlation with the $\mathrm{C} 4 \mathrm{aC}$. This quaternary carbon is indeed characterized by both its chemical shift at $\sim 100 \mathrm{ppm}$ and a long-range correlation observed with the $\mathrm{H} 4 \mathrm{C}$ protons. $\mathrm{OH} 5 \mathrm{~A}$ also correlated with two other carbons: the most deshielded $(\delta>145 \mathrm{ppm})$ was obviously C5A, while the other $(\delta>125 \mathrm{ppm})$ was $\mathrm{C} 6 \mathrm{~A}$, which also showed a correlation with the other OHA phenol proton, i.e., OH7A. This latter correlated with two other carbons: a deshielded quaternary carbon $(\delta>145 \mathrm{ppm})$ and a more shielded carbon $(\delta>125 \mathrm{ppm})$ which were easily attributed to $\mathrm{C} 7 \mathrm{~A}$ and $\mathrm{C} 8 \mathrm{~A}$, respectively. Once $\mathrm{C} 6 \mathrm{~A}$ and $\mathrm{C} 8 \mathrm{~A}$ are assigned, the residual HA proton may be directly attributed from the HSQC spectra. It thus was found that this residual HA proton was H6A for all fractions N2, N3, N4, N6. The IFL between catechin units thus implied a C8A position for all dimers.

\subsubsection{Determination of the B Ring Position of the IFL}

Dimers of fractions N2 and N4. The spectra of fraction N2 showed two different types of $\mathrm{B}$ ring proton spin systems: one AMX corresponding to the $\mathrm{B}$ ring of the nonlinked unit, and one $\mathrm{AM}$ with a coupling constant of about $8 \mathrm{~Hz}$, characteristic of $\mathrm{H} 6^{\prime} \mathrm{B}$ and $\mathrm{H} 5^{\prime} \mathrm{B}$ of a $\mathrm{C} 2^{\prime} \mathrm{B}$-linked unit. The linkage between the units of the $\mathrm{N} 2$ dimer is thus C2'B-C8A. The NMR spectra of fraction N4 also showed different B spin systems: two AMX, corresponding to the non-linked B-ring, and two AX spin systems, both displaying coupling constants of about $2 \mathrm{~Hz}$, which are characteristic of $\mathrm{H} 2^{\prime} \mathrm{B}$ and $\mathrm{H}^{\prime}{ }^{\prime} \mathrm{B}$ protons of $\mathrm{C} 5^{\prime} \mathrm{B}$-linked units. The presence of long-range ${ }^{1} \mathrm{H} /{ }^{13} \mathrm{C}$ correlations between $\mathrm{H} 6{ }^{\prime} \mathrm{B}$ and $\mathrm{C} 8 \mathrm{~A}$, which were observed in the HMBC spectra of the two dimers, are in accordance with a C5'B-C8A linkage (Figure 5).

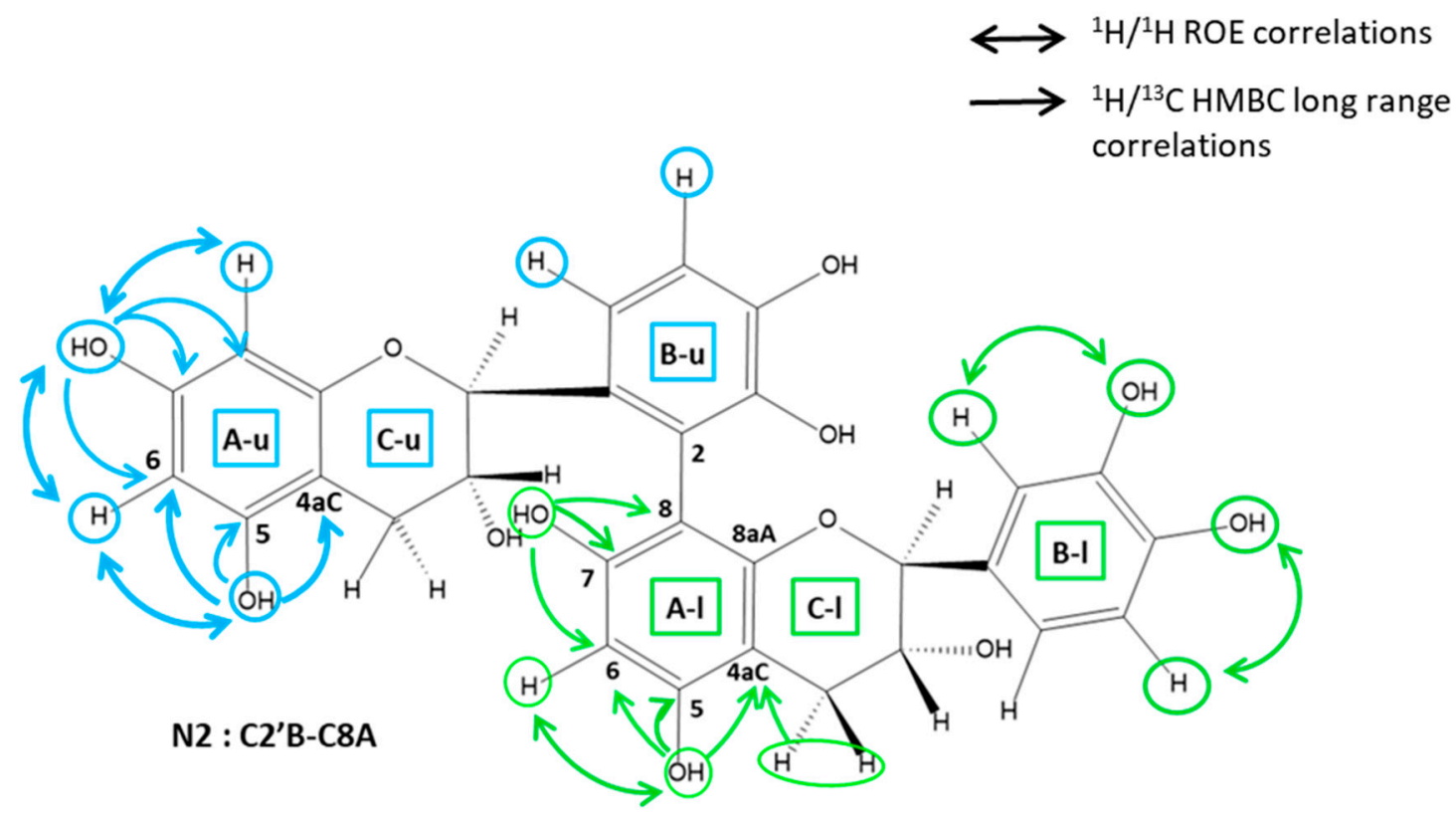

Figure 5. Cont. 

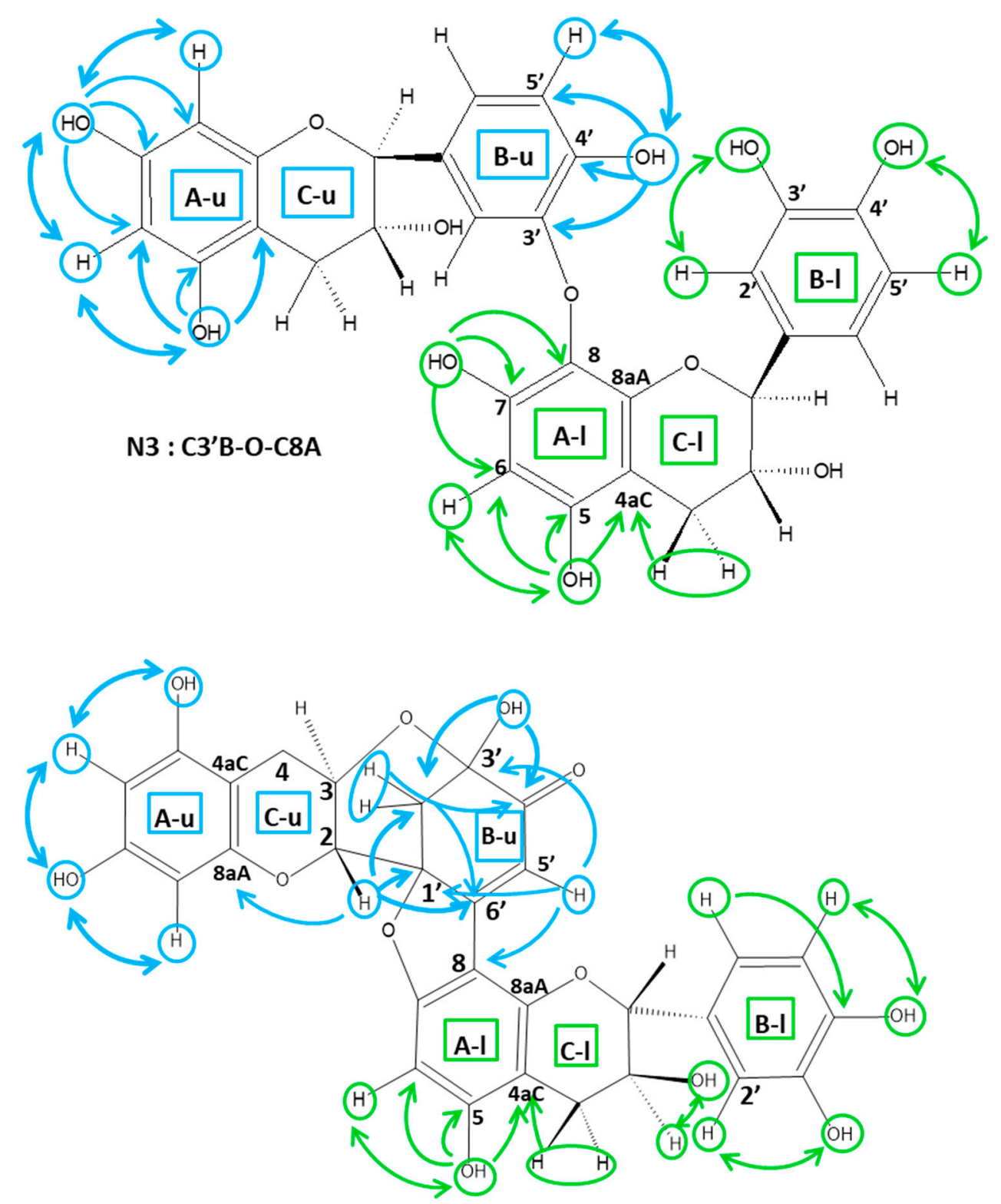

N8 : C'6B-C8A,C3-O-C3'B, C1'B-O-C7A

Figure 5. Scheme of catechin dimers (N2, N3, and N8) showing main ${ }^{1} \mathrm{H} /{ }^{13} \mathrm{C}$ long-range and ${ }^{1} \mathrm{H} /{ }^{1} \mathrm{H}$ ROE correlations, allowing linkage position determination. Blue arrows: upper unit. Green arrows: Lower units. Single arrows: HMBC correlations. Double arrows: ROEs correlations. A, B, C rings are labelled with u for upper units and with 1 for lower units.

Dimers of fractions N3 and N6. The spectra of fractions N3 and N6 showed the presence of two AMX B-ring proton systems and the lack of one $\mathrm{OH}$ phenol signal. Since all the OHA phenolic protons of the dimer units were identified (as described above), the missing $\mathrm{OH}$ phenolic signal can be either that of $\mathrm{OH} 3^{\prime} \mathrm{B}$ or that of $\mathrm{OH} 4^{\prime} \mathrm{B}$.

The $\mathrm{OH}$ position $\left(3^{\prime} \mathrm{B}\right.$ or $\left.4^{\prime} \mathrm{B}\right)$ may be easily determined through $\mathrm{ROE}$ correlations with $\mathrm{H}^{\prime}{ }^{\prime} \mathrm{B}$ or $\mathrm{H}^{\prime} \mathrm{B}$, respectively, or using long-range $\mathrm{HMBC}$ correlations as illustrated in Figure 5 . 
The attribution of the residual $\mathrm{OH}$ of the $\mathrm{B}$ rings was readily performed using either long-range HMBC or ROESY correlations, as illustrated in Figure 5. In the case of dimer N3, a ROE correlation was observed between the $\mathrm{H}^{\prime} \mathrm{B}$ and the residual $\mathrm{OH}^{\prime} \mathrm{B}$ of the catechin unit linked through its $\mathrm{B}$ ring. This $\mathrm{OH}$ was thus identified as $\mathrm{OH} 4^{\prime} \mathrm{B}$. In the case of fraction $\mathrm{N} 6$, the residual $\mathrm{OH}^{\prime} \mathrm{B}$ was assigned to $\mathrm{OH}^{\prime} \mathrm{B}$, since an $\mathrm{ROE}$ correlation was observed between this $\mathrm{OH}$ and $\mathrm{H}^{\prime}{ }^{\prime} \mathrm{B}$. The long-range $\mathrm{HMBC}$ correlations are in accordance with these attributions. The linkage positions of these two dimers were then determined as follows: $\mathrm{CO}^{\prime} \mathrm{B}-\mathrm{C} 8 \mathrm{~A}$ and $\mathrm{CO} 4^{\prime} \mathrm{B}-\mathrm{C} 8 \mathrm{~A}$ for $\mathrm{N} 3$ and N6. respectively.

Fraction N8. Spectrum analysis of the dimer N8 showed that one unit of this dimer is a catechin with two linkage positions one the $\mathrm{A}$ ring, one at the $\mathrm{C} 8 \mathrm{~A}$, and the other at the C-O7A position, since the protons H8A and OH7A are missing. The other unit of this dimer exhibited singular spectral features, indicating the loss of the B ring aromaticity and the presence of several linkage positions on both $B$ and $C$ rings.

The ${ }^{1} \mathrm{H}$ NMR signals arising from the $B$ ring were two doublets at 2.49 and $2.71 \mathrm{ppm}$, exhibiting a geminal coupling of $\sim 15 \mathrm{~Hz}(12.03 \mathrm{ppm})$ typical of a methylene group and a singlet at $6.38 \mathrm{ppm}$ arising from an ethylenic proton. Since these methylene and ethylene protons were not coupled, they are likely to be in positions $2^{\prime} \mathrm{B}$ and $5^{\prime} \mathrm{B}$. The HMBC spectrum showed all correlations, allowing accurate attributions of these B ring carbons, as illustrated in Figure 5. The $\mathrm{H} 2 \mathrm{C}$ of this unit gave three correlations with B ring carbons: one is the methylene carbon at $\sim 45 \mathrm{ppm}$, which was thus attributed to $C 2^{\prime} B$, and the remaining two, with carbons resonating at $\sim 90 \mathrm{ppm}$ and $\sim 162 \mathrm{ppm}$, which can be assigned to $\mathrm{C} 1^{\prime} \mathrm{B}$ and $\mathrm{C}^{\prime} \mathrm{B}$. $\mathrm{H} 5^{\prime} \mathrm{B}$ gave only strong ${ }^{3} \mathrm{~J}$ correlations with two quaternary carbons of this $\mathrm{B}$ ring: one is the carbon previously assigned to $\mathrm{C}^{\prime} \mathrm{B}(\sim 95 \mathrm{ppm})$, and the other one, which resonated at $\sim 90 \mathrm{ppm}$, could thus be attributed to $\mathrm{C} 1^{\prime} \mathrm{B}$. The carbon at $\sim 162 \mathrm{ppm}$ was then deduced to be $\mathrm{C}^{\prime} \mathrm{B}$.

The presence of an aliphatic $\mathrm{OH}(\sim 5.8 \mathrm{ppm})$ at the $\mathrm{C}^{\prime} \mathrm{B}$ position $(\sim 95 \mathrm{ppm})$ was determined through its ROE correlation with both $\mathrm{H}^{\prime}{ }^{\prime} \mathrm{B}$ protons. Furthermore, $\mathrm{OH} 3^{\prime} \mathrm{B}$ gave HMBC correlation with a quaternary carbon at $\sim 192.5 \mathrm{ppm}$, characteristic of a ketone group at the $\mathrm{C}^{\prime} \mathrm{B}$ position.

The shielding of this $\mathrm{C1}^{\prime} \mathrm{B}$ of about $40 \mathrm{ppm}$ is in accordance with a loss of the $\mathrm{B}$ ring aromaticity. Furthermore, the lack of $\mathrm{OH}$ at the $\mathrm{C} 7 \mathrm{~A}$ position of the other unit is in agreement with an ether linkage $\mathrm{C} 1^{\prime} \mathrm{B}-\mathrm{O}-\mathrm{C} 7 \mathrm{~A}$.

The NMR data showed that the $\mathrm{C}$ ring of this unit does not have any $\mathrm{OH} 3 \mathrm{C}$. The presence of a $\mathrm{C} 3 \mathrm{C}-\mathrm{O}-\mathrm{C} 3^{\prime} \mathrm{B}$ linkage is in accordance with the shielding of $\mathrm{C} 3 \mathrm{C}$ of about $1.5 \mathrm{ppm}$ as well as the chemical shift of $\mathrm{C}^{\prime} \mathrm{B}$ which is typical of a hemiketal carbon (95 ppm).

Altogether, the NMR spectral data allow us to conclude that this dimer corresponds to the dehydrocatechin A described earlier by Weinges et al. [33] and then by Guyot et al. [20].

The structures of the six dimeric compounds determined by these NMR analyses are shown in Figure 6, N2, N3, N6, and N8 being pure products, and N4 being a mixture of two isomers. 

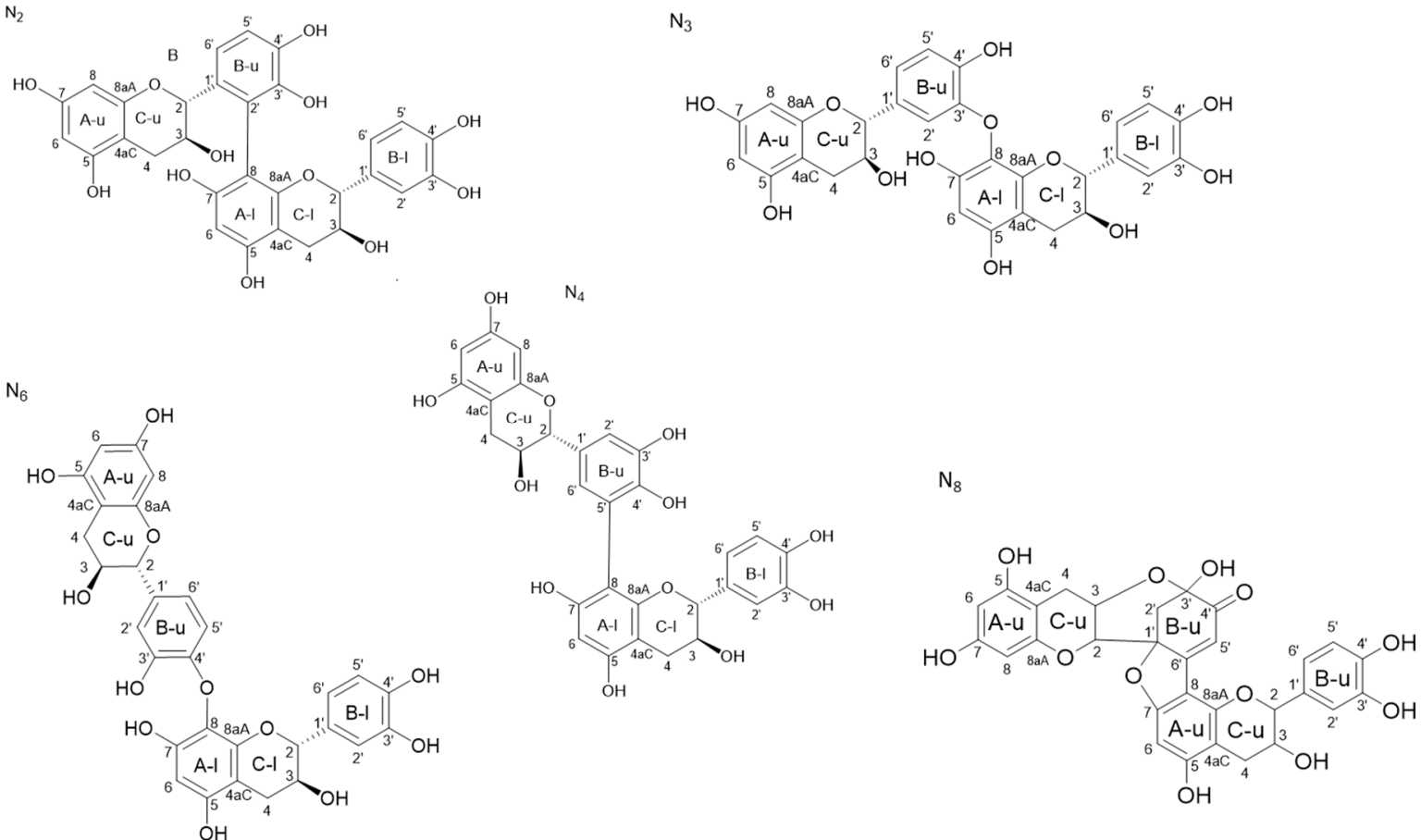

Figure 6. Structures of the six dimeric oxidation products formally identified by NMR analysis, N4 corresponding to a mixture of two isomers. Upper units rings are labelled with $\mathrm{u}$ and lower units rings are labelled with 1.

\section{Materials and Methods}

\subsection{Chemicals}

(+)-Catechin hydrate $\geq 98 \%$; laccase from Trametes versicolor $\left(0.94 \mathrm{U} \cdot \mathrm{mg}^{-1}\right)$; sodium phosphate dibasic dihydrate $\geq 98 \%$; citric acid (ACS reagent, cadmium nitrate tetrahydrate 99.997\%; formic acid and Amberlite XAD7HP were obtained from Sigma-Aldrich) (SaintLouis, MO, USA). Acetone- $d_{6}$ was purchased from Euriso-top (Saarbrücken, Germany), and trifluoroacetic acid (TFA) from Roth Labo (Karlsruhe, Germany). Water LC-MS, acetonitrile LC-MS (ACN), and methanol LC-MS (MeOH) were all from VWR (Radnor, PA, USA).

\subsection{Preparation of the Model Wine Solution}

The model wine solution was an ethanol/water solution $(12 / 88 ; v / v)$ with $0.033 \mathrm{M}$ tartaric acid, adjusted to $\mathrm{pH} 3.6$ with $\mathrm{NaOH} 1 \mathrm{M}$ [34].

\subsection{Crude Grape PPO Extracts}

The PPO extract was prepared as described previously by Singleton et al. [35]. Frozen grapes were first mixed in an acetate buffer $\left(1.5 \mathrm{M}, \mathrm{pH} 5 ; 10 \mathrm{~g} \cdot \mathrm{L}^{-1}\right.$ ascorbic acid). The mixture was then filtered and centrifuged (3000 g; $10 \mathrm{~min}$ ). The residue was finally washed with acetone $(80 \%)$ and air-dried.

\subsection{Laccase from Botrytis Cinerea}

Laccase from Botrytis cinerea was obtained as described by Quijada-Morin et al. [36]. It was produced from the VA612 strain (collected in 2005 in a vineyard in Hautvillers, Champagne, France, from the Pinot Noir cultivar). Briefly, cultures on solid malt yeast medium were left for one week at $24^{\circ} \mathrm{C}$ under blue light. The spores were then scraped and inoculated into a $500 \mathrm{~mL}$ Erlenmeyer flask containing $125 \mathrm{~mL}$ of culture medium (40 g. $\mathrm{L}^{-1}$ glucose, $7 \mathrm{~g} \cdot \mathrm{L}^{-1}$ glycerol, $0.5 \mathrm{~g} \cdot \mathrm{L}^{-1}$ L-histidine, $0.1 \mathrm{~g} \cdot \mathrm{L}^{-1} \mathrm{CuSO}_{4}, 1.8 \mathrm{~g} \cdot \mathrm{L}^{-1}$ $\mathrm{NaNO}_{3}, 0.5 \mathrm{~g} \cdot \mathrm{L}^{-1} \mathrm{KCl}, 0.5 \mathrm{~g} \cdot \mathrm{L}^{-1} \mathrm{CaCl}_{2} \cdot \mathrm{H}_{2} \mathrm{O}, 0.05 \mathrm{~g} \cdot \mathrm{L}^{-1} \mathrm{FeSO}_{4} \cdot 7 \mathrm{H}_{2} \mathrm{O}, 1.0 \mathrm{~g} \cdot \mathrm{L}^{-1} \mathrm{KH}_{2} \mathrm{PO}_{4}$, and $0.7 \mathrm{~g} \cdot \mathrm{L}^{-1} \mathrm{MgSO}_{4} \cdot 7 \mathrm{H}_{2} \mathrm{O}$ ). After 3 days of incubation and 2 days of growth in the same previous medium, gallic acid $\left(2 \mathrm{~g} \cdot \mathrm{L}^{-1}\right)$ was added to the pre-cultures. After 5 days, the 
liquid medium was filtered, and the supernatant was submitted to tangential filtration in a Quixstand filtration system (GE Healthcare UK, Little Chalfont, England) equipped with a $30 \mathrm{kDa}-$ molecular weight cut off membrane. The concentrate was finally subjected to a diafiltration against distilled water, and only the fractions that presented oxidant activity against ABTS were kept $\left(-80^{\circ} \mathrm{C}\right)$.

\subsection{Oxidation Procedure}

A laccase solution $\left(1 \mathrm{~g} \cdot \mathrm{L}^{-1}\right)$ in phosphate-citrate buffer was previously prepared and added to a $6 \mathrm{~g} \cdot \mathrm{L}^{-1}(+)$-catechin solution (model wine) to obtain a laccase final concentration of $0.3 \mathrm{~g} \cdot \mathrm{L}^{-1}$. The obtained solution was then slowly stirred $(180 \mathrm{rpm})$ at room temperature for $2 \mathrm{~h}$. The concentrations were previously optimized, and the experimentation was performed in triplicate.

\subsection{Reaction Stopping on Resin Amberlite XAD7HP}

An amberlite column was conditioned with ethanol (absolute) and rinsed with two column volumes of milli-Q water. The previous laccase/(+)-catechin reaction medium was dropped on the column and first eluted with two column volumes of milli-Q water [37]. The column was then eluted with ethanol until the collected fraction was uncolored. Only ethanol fractions were kept, evaporated, and lyophilized. The powder was stored at $-80^{\circ} \mathrm{C}$ until used.

\subsection{Purification Procedure of the Dimeric Fraction Using Flash Chromatography}

The lyophilized powder was first purified using a flash chromatography system puriflash430 equipped with a UV detector set at $280 \mathrm{~nm}$ and a Puriflash diol $50 \mu \mathrm{m}$ f0025 column. The binary mobile phase consisted of acetonitrile (solvent A) and methanol (solvent B), both acidified with $0.1 \%$ TFA. A series of injection were performed at a constant flow rate of $20 \mathrm{~mL} \cdot \mathrm{min}^{-1}$, using the following gradient: 100\% A for $4.4 \mathrm{~min}$; 0-10\% B in $10 \mathrm{~min}$; $10 \%$ B for $5 \mathrm{~min}$; $10-90 \%$ B in $5 \mathrm{~min} ; 90 \%$ B for $3 \mathrm{~min}$; $90-10 \%$ B in $2 \mathrm{~min}$; $10 \%$ B for $10 \mathrm{~min}$. The injection volume was $1 \mathrm{~mL}$ (300 mg lyophilized powder dissolved in $1 \mathrm{~mL}$ of solvent A). Three distinct fractions were collected each time. The first one corresponded to residual (+)-catechin, and the third one was a mixture of high-molecularweight polyphenols. The second eluted fraction, containing a mixture of dimeric oxidation products, was evaporated and lyophilized before the second purification step.

\subsection{Purification Procedure of Oxidation Products from the Dimeric Fraction Using a} Semi-Preparative Chromatographic System

The fraction containing dimeric oxidation products was purified using a semi-preparative Bio-Rad NGC 10 medium-pressure chromatography system equipped with a reversed-phase Varian Dynamax C18 Microsorb column $(250 \times 21.2 \mathrm{~mm} ; 3 \mu \mathrm{m})$. The binary mobile phase consisted of milli-Q water (solvent A) and 80\% acetonitrile, 20\% Milli-Q water (solvent B), both acidified with $0.05 \%$ TFA. A series of injections $(300 \mu \mathrm{L})$ of the lyophilized powder $(20 \mathrm{mg}$ dissolved in $200 \mu \mathrm{L}$ of solvent A and $100 \mu \mathrm{L}$ of ACN) were performed under the following elution conditions: 100\% A for $4 \mathrm{~min}$; 0-35\% B in 46 min; 35-100\% B in 2 min; 100\% B for 5 min. Eight distinct fractions were collected each time, corresponding to pure UPLC signals at $280 \mathrm{~nm}$. Each fraction was evaporated and lyophilized before NMR analysis.

\subsection{Sample Preparation for NMR Analysis}

About $1 \mathrm{mg}$ of each lyophilized powder weighted in Eppendorf tubes was solved into $500 \mu \mathrm{L}$ of acetone $-d_{6}$. Then, $\sim 10 \mu \mathrm{L}$ of a concentrated solution of cadmium nitrate in acetone- $d_{6}$ was added to the samples, and the resulting solutions were transferred to $5 \mathrm{~mm}$ NMR tubes for NMR analysis. An additional step was performed for some samples: after solubilization of the lyophilized powders in acetone- $d_{6}$ in the presence of traces of 
cadmium, the samples were evaporated to dryness and then re-solubilized in acetone- $d_{6}$ without further addition of $\mathrm{Cd}$.

\subsection{Instrument Specifications}

UPLC-MS analysis. The reactions were monitored using two UPLC-MS systems. The first one was used to precisely identify products' retention times using a long gradient method. i.e., Waters reversed-phase Ultra-High-Performance Liquid Chromatography coupled to Mass Spectrometry (UHPLC-MS). The liquid chromatography system was an Acquity UPLC (Waters, Milford, MA, USA) equipped with a photodiode array detector. We used an Acquity UPLC HSS T3 column $(1.8 \mu \mathrm{m}, 2.1 \times 150 \mathrm{~mm})$. The column temperature was $25^{\circ} \mathrm{C}$. The binary mobile phase consisted of $0.1 \%$ formic acid in water (solvent A) and acetonitrile (solvent $\mathrm{B}$ ). The separation was performed at a constant flow rate of $0.25 \mathrm{~mL} \cdot \mathrm{min}^{-1}$, using the following gradient: $8-11 \% \mathrm{~B}$ in $2 \mathrm{~min}$; $11 \% \mathrm{~B}$ for $8 \mathrm{~min} ; 11-25 \% \mathrm{~B}$ in $15 \mathrm{~min}$; $25-55 \%$ B in $5 \mathrm{~min}$; $55-99 \%$ B in $1 \mathrm{~min}$; $99 \%$ B for $4 \mathrm{~min}$; $99-8 \%$ B in $1 \mathrm{~min}$; $8 \%$ B for $4 \mathrm{~min}$. The injection volume was $5 \mu \mathrm{L}$. The mass spectrometer was a Waters Acquity QDa electrospray ionization (ESI) simple quadrupole (Waters, Milford, MA, USA). The capillary voltage was set at $0.8 \mathrm{kV}$. The mass spectra were acquired over a mass range of 200-900 Th in the positive ion mode.

The second UHPLC-MS system, used for a rapid verification during the purification steps, was the same as described previously, with an Acquity UHPLC HSS T3 column $(1.8 \mu \mathrm{m}, 2.1 \times 100 \mathrm{~mm})$ heated at $38^{\circ} \mathrm{C}$. The separation was performed at a constant flow rate of $0.55 \mathrm{~mL} \cdot \mathrm{min}^{-1}$, using the following fast gradient: $0.1-40 \%$ B in $5 \mathrm{~min} ; 40-99 \%$ $\mathrm{B}$ in $2 \mathrm{~min}$; $99 \%$ B for $1 \mathrm{~min}$; $99-0.1 \%$ B in $1 \mathrm{~min}$. The injection volume was $2 \mu \mathrm{L}$. The mass spectrometer was a Bruker amaZon X electrospray ionization (ESI) ion trap (Bruker Daltonics, Bremen, Germany). The capillary voltage was set at $-5.5 \mathrm{kV}$. The mass spectra were acquired over a mass range of 50-2000 Th in the positive ion mode.

All UPLC-MS analyses were performed in triplicate.

NMR Instrumentation. All the NMR spectra were recorded on an Agilent DD2 $500 \mathrm{MHz}$ spectrometer (Agilent Technologies, Santa Clara, CA, USA), operating at 500.05 and $125.74 \mathrm{MHz}$ for proton and carbon- 13 nuclei, respectively, using a $5 \mathrm{~mm}$ indirect detection probe equipped with a z gradient coil. $1 \mathrm{D}^{1} \mathrm{H}$ and ${ }^{13} \mathrm{C}, 2 \mathrm{D}$ homonuclear ${ }^{1} \mathrm{H}$ TOCSY and ROESY, and heteronuclear ${ }^{1} \mathrm{H} /{ }^{13} \mathrm{C}$ HSQC and HMBC experiments were performed using classical pulse sequences and analyzed using both VNMRJ4.2 and MestReNova 14.2.1 (Mestrelab Research, Spain) software. DOSY measurements were acquired and processed as previously described [38]. The acquisition parameters of the DgcsteSL pulse sequence were as follows: the diffusion delay time and the gradient pulse width were set at $50 \mathrm{~ms}$ and $2 \mathrm{~ms}$, respectively, the gradient strength $(\mathrm{g})$ was incremented in 16 steps with equal g2 spacing from 0.3 to $32 \mathrm{G} \cdot \mathrm{cm}^{-1}$. After phase correction, 2D DOSY spectra were constructed from the peak height measurement using VNMRJ4.2 software.

All spectra were referenced to the solvent acetone- $d_{6}$ signals $\left({ }^{1} \mathrm{H}\right.$ residual signal at $2.05 \mathrm{ppm}$ and ${ }^{13} \mathrm{C}$ signal at $\left.29.92 \mathrm{ppm}\right)$.

\section{Conclusions}

The action of three different oxidoreductases (polyphenoloxidase extracted from grapes, laccase from Botrytis cinerea, and laccase from Trametes versicolor) on (+)-catechin were investigated, and the LC-UV-MS resulting profiles were very similar, although some minor differences suggested possible dissimilarities in the reactivity of these enzymes.

The structures of six catechin-laccase oxidation products (using laccase from Trametes versicolor) were obtained on the basis of specific NMR signatures (four pure products, i.e., $\mathrm{N} 2, \mathrm{~N} 3, \mathrm{~N} 6$, and N8, and N4, corresponding to a mixture of two isomers). The complete attribution of phenolic $\mathrm{OH}$ signals was possible thanks to the addition of cadmium nitrate with a simple preparation procedure that allowed the unambiguous attribution of the linkages between the catechin units for some of the compounds of interest. This procedure 
will greatly simplify NMR analysis of polyphenols mixtures, either synthetized or extracted from natural products.

The standards obtained in this work may be used in the future as oxidation markers to investigate their presence and evolution during grape ripening and wine ageing. Besides catechin, other polyphenol compounds, including flavonoids and non-flavonoids, may also be used as substrates of laccase to obtain additional new standards.

Supplementary Materials: The following are available online, Figure S1: Classification of enzymes responsible for enzymatic browning; Table $\mathrm{S} 1:{ }^{1} \mathrm{H}$ and ${ }^{13} \mathrm{C}$ NMR assignments for compounds N2, $\mathrm{N} 3, \mathrm{~N} 4, \mathrm{~N} 6$, and N8; Figure S2: $2 \mathrm{D}^{1} \mathrm{H} /{ }^{13} \mathrm{C}$ HMBC, top $1 \mathrm{D}^{1} \mathrm{H}$, side $1 \mathrm{D}^{13} \mathrm{C}$ spectrum (a) N2; (b) N3; (c) N4; (d) N6, and (e) N8; Figure S3: ${ }^{1} \mathrm{H}$ 2D ROESY spectrum showing correlations (in blue) between phenolic and aromatic protons, ROE correlations between phenolic protons due to chemical exchange appear in red (a) N2, (b) N3, (c) N4, (d) N6, and (e) N8.

Author Contributions: Conceptualization: C.S.; Data curation: S.D.; Formal analysis: S.D.; Funding acquisition: C.S.; Investigation: S.D. and C.I.G.; Methodology: S.D., L.S., C.1.G. and C.S.; Project administration and validation: C.S.; Supervision: L.M., F.G. and C.S.; Visualization: S.D.; Writingoriginal draft: S.D.; Writing—review and editing: S.D., C.S., L.M., F.G., L.S. and C.1.G. All authors have read and agreed to the published version of the manuscript.

Funding: This work was supported in part by a PhD grant (S.D.) from the University of Montpellier (Bourse école doctorale GAIA).

Institutional Review Board Statement: Not applicable.

Informed Consent Statement: Not applicable.

Data Availability Statement: The data presented in this study are available in the present article and Supplementary Information Section.

Conflicts of Interest: The authors declare no conflict of interest.

Sample Availability: Samples of the compounds are not available from the authors.

\begin{abstract}
Abbreviations
NMR: nuclear magnetic resonance, Cd: cadmium, TOCSY: total correlation spectroscopy, ROESY: Rotating-frame nuclear Overhauser effect spectroscopy, HSQC: heteronuclear single-quantum correlation experiment, HMBC: heteronuclear multi-bond connectivity, DOSY: diffusion ordered spectroscopy.
\end{abstract}

\title{
References
}

1. Khan, N.; Mukhtar, H. Tea Polyphenols for Health Promotion. Life Sci. 2007, 81, 519-533. [CrossRef]

2. Fayeulle, N.; Vallverdu-Queralt, A.; Meudec, E.; Hue, C.; Boulanger, R.; Cheynier, V.; Sommerer, N. Characterization of New Flavan-3-Ol Derivatives in Fermented Cocoa Beans. Food Chem. 2018, 259, 207-212. [CrossRef] [PubMed]

3. Rimbach, G.; Melchin, M.; Moehring, J.; Wagner, A.E. Polyphenols from Cocoa and Vascular Health-A Critical Review. Int. J. Mol. Sci. 2009, 10, 4290-4309. [CrossRef]

4. Avram, A.M.; Morin, P.; Brownmiller, C.; Howard, L.R.; Sengupta, A.; Wickramasinghe, S.R. Concentrations of Polyphenols from Blueberry Pomace Extract Using Nanofiltration. Food Bioprod. Process. 2017, 106, 91-101. [CrossRef]

5. Antoniolli, A.; Fontana, A.R.; Piccoli, P.; Bottini, R. Characterization of Polyphenols and Evaluation of Antioxidant Capacity in Grape Pomace of the Cv. Malbec. Food Chem. 2015, 178, 172-178. [CrossRef]

6. Saucier, C. How Do Wine Polyphenols Evolve during Wine Ageing? Cerevisia 2010, 35, 11-15. [CrossRef]

7. Oliveira, C.M.; Ferreira, A.C.S.; De Freitas, V.; Silva, A.M.S. Oxidation Mechanisms Occurring in Wines. Food Res. Int. 2011, 44, 1115-1126. [CrossRef]

8. Singleton, V.L. Oxygen with Phenols and Related Reactions in Musts, Wines, and Model Systems: Observations and Practical Implications. Am. J. Enol. Vitic. 1987, 38, 69-77.

9. Mathew, A.G.; Parpia, H.A.B. Food Browning as a Polyphenol Reaction. In Advances in Food Research; Chichester, C.O., Mrak, E.M., Stewart, G.F., Eds.; Academic Press: Cambridge, MA, USA, 1971; Volume 19, pp. 75-145. [CrossRef]

10. Gambuti, A.; Rinaldi, A.; Ugliano, M.; Moio, L. Evolution of Phenolic Compounds and Astringency during Aging of Red Wine: Effect of Oxygen Exposure before and after Bottling. J. Agric. Food Chem. 2013, 61, 1618-1627. [CrossRef] [PubMed] 
11. Caillé, S.; Samson, A.; Wirth, J.; Diéval, J.-B.; Vidal, S.; Cheynier, V. Sensory Characteristics Changes of Red Grenache Wines Submitted to Different Oxygen Exposures Pre and Post Bottling. Anal. Chim. Acta 2010, 660, 35-42. [CrossRef]

12. Dubernet, M.; Ribereau-Gayon, P.; Lerner, H.R.; Harel, E.; Mayer, A.M. Purification and Properties of Laccase from Botrytis Cinerea. Phytochemistry 1977, 16, 191-193. [CrossRef]

13. Li, H.; Guo, A.; Wang, H. Mechanisms of Oxidative Browning of Wine. Food Chem. 2008, 108, 1-13. [CrossRef]

14. Ployon, S.; Attina, A.; Vialaret, J.; Walker, A.S.; Hirtz, C.; Saucier, C. Laccases 2 \& 3 as Biomarkers of Botrytis Cinerea Infection in Sweet White Wines. Food Chem. 2020, 315, 126233. [CrossRef]

15. Robards, K.; Prenzler, P.D.; Tucker, G.; Swatsitang, P.; Glover, W. Phenolic Compounds and Their Role in Oxidative Processes in Fruits. Food Chem. 1999, 66, 401-436. [CrossRef]

16. Sánchez-Ferrer, Á.; Neptuno Rodríguez-López, J.; García-Cánovas, F.; García-Carmona, F. Tyrosinase: A Comprehensive Review of Its Mechanism. Biochim. Biophys. Acta BBA-Protein Struct. Mol. Enzymol. 1995, 1247, 1-11. [CrossRef]

17. Du Toit, W.J.; Marais, J.; Pretorius, I.S.; du Toit, M. Oxygen in Must and Wine: A Review. S. Afr. J. Enol. Vitic. 2006, 27, 76-94. [CrossRef]

18. Kutyrev, A.A.; Moskva, V.V. Nucleophilic Reactions of Quinones. Russ. Chem. Rev. 1991, 60, 72. [CrossRef]

19. Guyot, S.; Cheynier, V.; Souquet, J.M.; Moutounet, M. Influence of PH on the Enzymic Oxidation of (+)-Catechin in Model Systems. J. Agric. Food Chem. 1995, 43, 2458-2462. [CrossRef]

20. Guyot, S.; Vercauteren, J.; Cheynier, V. Structural Determination of Colourless and Yellow Dimers Resulting from (+)-Catechin Coupling Catalysed by Grape Polyphenoloxidase. Phytochemistry 1996, 42, 1279-1288. [CrossRef]

21. Sun, W.; Miller, J.M. Tandem Mass Spectrometry of the B-Type Procyanidins in Wine and B-Type Dehydrodicatechins in an Autoxidation Mixture of (+)-Catechin and (-)-Epicatechin. J. Mass Spectrom. 2003, 38, 438-446. [CrossRef]

22. Jiménez-Atiénzar, M.; Cabanes, J.; Gandía-Herrero, F.; García-Carmona, F. Kinetic Analysis of Catechin Oxidation by Polyphenol Oxidase at Neutral PH. Biochem. Biophys. Res. Commun. 2004, 319, 902-910. [CrossRef]

23. Cheynier, V.; Basire, N.; Rigaud, J. Mechanism of Trans-Caffeoyltartaric Acid and Catechin Oxidation in Model Solutions Containing Grape Polyphenoloxidase. J. Agric. Food Chem. 1989, 37, 1069-1071. [CrossRef]

24. López-Serrano, M.; Ros Barceló, A. Reversed-Phase and Size-Exclusion Chromatography as Useful Tools in the Resolution of Peroxidase-Mediated (+)-Catechin Oxidation Products. J. Chromatogr. A 2001, 919, 267-273. [CrossRef]

25. Mouls, L.; Fulcrand, H. UPLC-ESI-MS Study of the Oxidation Markers Released from Tannin Depolymerization: Toward a Better Characterization of the Tannin Evolution over Food and Beverage Processing: Oxidation Markers Released from Tannin Depolymerization. J. Mass Spectrom. 2012, 47, 1450-1457. [CrossRef] [PubMed]

26. Mouls, L.; Fulcrand, H. Identification of New Oxidation Markers of Grape-Condensed Tannins by UPLC-MS Analysis after Chemical Depolymerization. Tetrahedron 2015, 71, 3012-3019. [CrossRef]

27. López-Serrano, M.; Ros Barceló, A. Comparative Study of the Products of the Peroxidase-Catalyzed and the PolyphenoloxidaseCatalyzed (+)-Catechin Oxidation. Their Possible Implications in Strawberry (Fragaria $\times$ Ananassa) Browning Reactions. J. Agric. Food Chem. 2002, 50, 1218-1224. [CrossRef]

28. Appeldoorn, M.M.; Sanders, M.; Vincken, J.P.; Cheynier, V.; Le Guernevé, C.; Hollman, P.C.H.; Gruppen, H. Efficient Isolation of Major Procyanidin A-Type Dimers from Peanut Skins and B-Type Dimers from Grape Seeds. Food Chem. 2009, 117, 713-720. [CrossRef]

29. Es-Safi, N.E.; Guernevé, C.L.; Ducrot, P.H. Application of NMR Spectroscopy and Mass Spectrometry to the Structural Elucidation of Modified Flavan-3-ols and Their Coupling Reaction Products*. Spectrosc. Lett. 2008, 41, 41-56. [CrossRef]

30. De Bruyne, T.; Pieters, L.A.C.; Dommisse, R.A.; Kolodziej, H.; Wray, V.; Domke, T.; Vlietinck, A.J. Unambiguous Assignments for Free Dimeric Proanthocyanidin Phenols from 2D NMR. Phytochemistry 1996, 43, 265-272. [CrossRef]

31. Charisiadis, P.; Primikyri, A.; Exarchou, V.; Tzakos, A.; Gerothanassis, I.P. Unprecedented Ultra-High-Resolution Hydroxy Group 1H NMR Spectroscopic Analysis of Plant Extracts. J. Nat. Prod. 2011, 74, 2462-2466. [CrossRef]

32. Esatbeyoglu, T.; Jaschok-Kentner, B.; Wray, V.; Winterhalter, P. Structure Elucidation of Procyanidin Oligomers by LowTemperature 1H NMR Spectroscopy. J. Agric. Food Chem. 2011, 59, 62-69. [CrossRef] [PubMed]

33. Weinges, K.; Ebert, W.; Huthwelker, D.; Mattauch, H.; Perner, J. Oxydative Kupplung von Phenolen, II1) Konstitution und Bildungsmechanismus des Dehydro-dicatechins A. Justus Liebigs Ann. Chem. 1969, 726, 114-124. [CrossRef]

34. Zou, H.; Kilmartin, P.A.; Inglis, M.J.; Frost, A. Extraction of Phenolic Compounds during Vinification of Pinot Noir Wine Examined by HPLC and Cyclic Voltammetry. Aust. J. Grape Wine Res. 2002, 8, 163-174. [CrossRef]

35. Singleton, V.L.; Salgues, M.; Zaya, J.; Trousdale, E. Caftaric Acid Disappearance and Conversion to Products of Enzymic Oxidation in Grape Must and Wine. Am. J. Enol. Vitic. 1985, 36, 50-56.

36. Quijada-Morin, N.; Garcia, F.; Lambert, K.; Walker, A.S.; Tiers, L.; Viaud, M.; Sauvage, F.X.; Hirtz, C.; Saucier, C. Strain Effect on Extracellular Laccase Activities from Botrytis Cinerea. Aust. J. Grape Wine Res. 2018, 24, 241-251. [CrossRef]

37. Spinelli, D.; Fatarella, E.; Di Michele, A.; Pogni, R. Immobilization of Fungal (Trametes Versicolor) Laccase onto Amberlite IR-120 H Beads: Optimization and Characterization. Process Biochem. 2013, 48, 218-223. [CrossRef]

38. Watrelot, A.A.; Le Guernevé, C.; Hallé, H.; Meudec, E.; Véran, F.; Williams, P.; Robillard, B.; Garcia, F.; Poncet-Legrand, C.; Cheynier, V. Multimethod Approach for Extensive Characterization of Gallnut Tannin Extracts. J. Agric. Food Chem. 2020, 68, 13426-13438. [CrossRef] 